\title{
VALORES INTENCIONAIS E PERSUASIVOS DA LÍNGUA JAPONESA
}

Lídia Masumi Fukasawa

RESUMO: Partindo da idéia de que a língua é uma conseqüêcia de hábitos socioculturais, este trabalho se propõe a levantar e discutir alguns dos valores convencionais (ou cristalizaçōes) desenvolvidos no interior da cultura japonesa, tidos como consagrados e otimizados pelo seu uso e que determinam e norteiam os mecanismos de argumentação em japonês.

ABSTRACT: Starting from the point of view that language is a consequence of sociocultural usages, this paper intends to draw up and discuss some of the conventional values (or crystallizations) developed inside the bounderies of japanese culture which are considered renowned and recognized by their use and that determine and guide the argumentative mechanisms in japanese language.

PALAVRAS-CHAVE: argumentação em japonês, valores culturais e enunciativos da língua japonesa, estratégias comunicativas em japonês.

KEYWORDS: argumentation in Japanese, cultural and ennuniciative values in Japanese language, communication strategies in Japanese.

Se a língua é uma consequiência de hábitos socioculturais, abordar seus aspectos semântico-argumentativos implica necessariamente levar-se em conta concepções convencionais e cristalizações (ou "formas tópicas", segundo a terminologia de Ducrot), retidas e desenvolvidas no interior da sua cultura. Investigar, portanto, a língua japonesa, pressupõe o conhecimento de certos valores de sua cultura, que dizem respeito aos modos de exprimir hábitos sociais, esperados e tidos como consagrados e otimizados pelo seu próprio uso. Admitindo-se então que o ponto de vista encontra-se, via de regra, 
corporificado em crenças e mitos determinados pela cultura, a língua, em última instância, refletirá esses modos de pensamento e de conduta.

Como aspecto relevante e indispensável na investigação e na compreensão do mecanismo de argumentação da língua japonesa, procurar-se-á, aqui, levantar alguns desses valores e conceitos culturais que dizem respeito ao japonês e que já se encontram amplamente reconhecidos não só por lingüistas, mas por alguns dos antropólogos culturais, sociólogos e psicólogos japoneses.

É preciso lembrar, inicialmente, o princípio do Tsutaeru ishiga nai mamani tsutawaru ("as coisas são transmitidas sem que haja intenção para isso"), levantado por Araki (1973, 1976 e 1980), Kindaichi (1980), Haga (1979), Ôno (1967) entre outros, e que vem a caracterizar, de modo geral, a expressividade da língua japonesa.

Se se considera a língua e a comunicação como fator básico de transmissão da intenção e da argumentação do locutor e a posição que o locutor assumiu de acordo com as regras sociais, parece ficar contraditório dizer que o japonês "acaba comunicando, sem que tenha havido intenção de fazê-lo". Mas a verdade é que, muitas vezes, a tão decantada intencionalidade não fica muito clara no enunciado japonês, no qual se estabelece, como conseqüência, algo "semelhante a uma comunicação" (no sentido intencional), isto é, a ocorrência de uma quase-comunicação como diz Haga (1979, p. 22). Comunicação ou "falsa comunicação" são apenas modos de denominar a interação. O que importa é que essa "quase-comunicação", como a denomina Haga, nada mais é do que uma técnica de criação de efeito de sentido, através da qual o locutor japonês procura comunicar suas intenções ao destinatário de forma a que este não perceba essas intenções. Trata-se, enfim, de um recurso de criação de sentido e de intencionalidade, mediante uso de recursos discursivos diferentes daqueles comumente utilizados no Ocidente. E esse recurso desempenha, em termos de língua japonesa, um resultado importante no seu aspecto interativo. A verdade é que os japoneses parecem não apreciar muito as formas e os modos que exprimem a intencionalidade de maneira clara e explícita, haja vista que procuram, inclusive, evitar indagações sobre os sentimentos ou as razões dos outros e mesmo verificações ou confirmações das opiniões dos parceiros do diálogo. Haga afirma que os japoneses "vivem dentro de uma cultura na qual os homens não se explicam muito entre si" (1979, p. 22). Vale a pena lembrar que essa é uma das características da cultura japonesa enfatizada não só por Haga, mas por Araki, Sakakura, Kindaichi, Okuyama, Aida e muitos outros autores.

Tal característica parece ter, em sua base, dois fatores fundamentais que a explicam: de um lado, a crença dos japoneses de que os sentimentos humanos não podem ser expressos, em sua totalidade e em sua profundidade, pela língua (a descrença no valor absoluto da língua para comunicar, à semelhança da noção do "eu inefável" proposto por Benveniste); de outro, a própria condição sócio-histórica por que passaram os japoneses ao longo dos tempos - o Japão, originariamente, uma sociedade agrícola, um mundo pequeno e restrito, cercado pelos limites geográficos (cuja base era o vilarejo), apresentava-se como um mundo místico e fechado, onde os deuses constituíam entidades do sistema coletivo, em prol da proteção do vilarejo. Eram identificados em todos os elementos da natureza e negavam o princípio do individualismo, em função da afirmação do coletivo. Assim, na cultura japonesa, o indivíduo significava apenas um membro da 
coletividade, um dos elementos que a compōem, donde as relações não serem freqüentemente realizadas mediante interações do tipo indivíduo/indivíduo, mas do tipo indivíduo/coletividade. Em Nihongokara Nihonjin o Kangaeru (Analisar o Japonês pela sua Língua) 1980, o antropólogo e linguiista Araki Hiroyuki aponta, como ponto de partida para a análise do japonês, essas diferenças de circunstâncias históricas que caracterizam o povo japonês e os povos ocidentais. Para ele, a distinção mais fundamental está no fato de ter sido a cultura ocidental (mais especificamente a indo-européia) uma cultura essencialmente nômade enquanto a japonesa era basicamente agrícola. Na cultura ocidental, continua, o nomadismo tem como base a "economia de ocupação", na qual surge a necessidade do estabelecimento de uma "lógica do contrato" a ser firmado entre os homens, na luta pela sua sobrevivência. Deste modo, os povos nômades desenvolveram o espírito do individualismo, cuja base é encontrada na noção de que a real existência do homem está vinculada ao sentido de solidão e na concepção da consciência de confronto entre os indivíduos. Aos indivíduos, portanto, ligados por essa relação de confrontação, era inevitável a experimentação da sensação de medo diante da morte, de consciência de perda ou quebra, donde seu objetivo de vida se torna a busca da felicidade individual e donde a ruptura possível entre os indivíduos só podia ser superado pelo contrato ou pelo princípio do "amor cristão" que surge do Deus único do Cristianismo. Ao contrário, prossegue ainda o autor, o povo japonês procurava - pelas próprias necessidades que advêm de se viver constantemente em uma comunidade pequena, onde os homens precisavam unir suas forças para produzir e garantir sua sobrevivência - cultuar o princípio da harmonia $(w a)$, um valor que só se torna significativo no interior de uma comunidade sedentariamente estabelecida e de características eminentemente coletivas.

Dentro dessa perspectiva, a concepção de "indivíduo" se torna um valor a ser evitado e descartado, em benefício dessa estrutura de coletividade. Em última análise, a negação do individualismo significava a afirmação da coletividade, onde o indivíduo não é senão um elemento da construção do grupo, unificado pela lógica do sistema coletivo.

Enquanto o "amor" é a lógica da existência mútua dos indivíduos, a "harmonia" (wa) é uma moral de solidariedade que deve ser perpetuada dentro do sistema de coletividade. "A base da diferença entre essas duas concepções propicia a divergência na valoração de mundo das duas culturas" (Araki, 1980, p. 72).

Baseado nas idéias propostas pelo antropólogo japonês Ishida Eiichirô, o psicolingüista Haga Yasushi (1979) chega também a conclusões semelhantes. Para os povos europeus, diz, que construíram e desenvolveram, depois da civilização grega, sociedades fundamentalmente comerciais, era extremamente importante a intensidade com que os indivíduos expressavam suas intenções e seus sentimentos. Era preciso, não só especificar e explicitar as posições individuais, mas enfatizá-las. Assim, os dois pilares que sustentavam a cultura ocidental - a Lógica e a Retórica - não se afiguravam como conhecimentos indispensáveis para os japoneses.

Para os japoneses, a Lógica parecia ser uma teoria que apenas elaborava sofismas e jogos de palavras que não se relacionavam em nada com a realidade, e a Retórica, uma mera técnica de enfeitar a palavra e camuflar a verdade. Mas mesmo sendo a 
Retórica uma técnica de bem desenvolver a argumentação e a expressão dos sentimentos ou das intenções do locutor, relacionadas aos fatos, para os japoneses, essa técnica também era algo dispensável. Por outro lado, o princípio da coletividade possibilitava uma compreensão harmoniosa entre os indivíduos. Viver numa pequena comunidade significava menor exposição ao desentendimento (e, como conseqüência, menor confronto com o perigo) e maior compatibilidade com a harmonia entre os indivíduos. Significava menor necessidade de argumentatividade e persuasão ${ }^{1}$, visto que todos agiam e viviam em função de um único objetivo comum, no qual o aspecto conflitante encontra pouco espaço para se efetivar como problema a ser discutido e resolvido. A argumentatividade tem como função esclarecer e enfatizar o meu "eu", a minha existência e o meu modo de ver. Para os japoneses, era mais importante usar, ao invés da argumentatividade e da persuasão explícita, a sabedoria do "não falar, para preservar o eu e a coletividade". Por outro lado, a sua visão de mundo, fundamentalmente baseada na natureza, isto é, na crença de que todos os acontecimentos da vida constituem nada mais do que o "desenrolar natural" dos fatos (shizen tenkai, no dizer de Araki), independente da interferência da vontade dos homens, também apresenta suas marcas na linguagem. A natureza, para o japonês, não é absolutamente algo contra o qual deva lutar ou algo que deva desafiar; ao contrário, ele acredita ser parte integrante dela. Esse ponto de vista propicia a tendência japonesa de uma certa aversão por tudo aquilo que parece artificial ou não natural. Quanto mais próximo do "natural", melhor. Retratar o mundo da natureza significa retratar o homem, e essa consciência, enquanto valor positivo, permanece como tal desde a época da antologia poética Man'yôshû (século VIII), até o haiku moderno.

Seguindo-se essa mesma linha de raciocínio, pode-se concluir que os métodos de se atingir um certo objetivo com avidez, mediante destruição dos obstáculos, não são próprios do gosto dos japoneses. Ao invés da insistência e da obstinação, preferem a moderação (hodo hodoni) e a resignação (akirame), diz Haga.

Essa atitude de resignação, por outro lado, propiciou a aceitação de certos ensinamentos do Budismo proveniente da China (que vieram a se somar às suas outras características), como é o caso da incorporação da noção de mujô, isto é, o conceito de "efemeridade da vida" e de "mutabilidade das coisas". Dessa aceitação, decorre, como consequiência, a atitude da não-divisão nítida e da não-oposição das coisas: tudo é transitório, tudo é mutável. O método cognitivo da não-discriminação e da não-divisão das coisas, por seu turno, privilegiou o método do "sentir intuitivo" por meio das sensações, mais do que o método direto e o de explicar através da língua.

Surge, então, a máxima de "não se falar tudo, detalhadamente". Em outras palavras, a tendência de não contornar rigidamente as linhas significativas das coisas e dos fatos, mas deixá-las com a impressão de que são imprecisas e vagas.

Verificar-se-ão, portanto, certos preceitos estéticos de comportamento comunicativo (e, diga-se de passagem, que resistiram aos tempos e se conservam até os dias de hoje), tais como: kataranuga hana (literalmente, "o não-expressar é a flor"), no

1. A questão parece não estar ligada tanto à noção de "menor necessidade de argumentação", mas, antes, à idéia de que os japoneses argumentam de forma diferente, isto é, recorrem a outros recursos para a argumentação e a interação. 
sentido de "melhor não exprimir verbalmente em discurso"; ou narubeku monoo iwanai ("procurar falar o menos possível"); o valor estético da implicitação, da lítotes, do hyôgen'o bokasu ("deixar a expressão vaga e imprecisa"); enfim, a idéia de que se deve apoiar o mínimo possível na língua para a interação se tornar mais eficaz e harmoniosa. A propósito desse aspecto, Okuyama (1972, p. 215) chama a atenção para as duas tendências diversas que caracterizam cada qual a sua linguagem: para os ocidentais, a função primordial do ato de fala é a ênfase do "eu"; ao contrário, para o japonês, é a técnica segundo a qual o locutor procura se "preservar", mediante atitude de não enunciar, ou ainda, fazê-lo utilizando-se de formas apenas cerimoniais (tatemaeno katachi). Paradoxalmente, o sentido de "preservar o eu" parece ser, ao mesmo tempo, o outro lado da moeda, isto é, o de incluir o sentido de jiko hitei ("negação do eu"), possivelmente também proveniente da observância de um ensinamento religioso búdico.

Para os japoneses, ainda segundo Okuyama, mais do que a atitude de centralizar a figura do "eu" no discurso, o ato de falar baseia-se, antes, na importância que o locutor atribui ao seu destinatário. Assim, o esquema persuasivo do locutor japonês é mais orientado pela sua preocupação a respeito do modo pelo qual vai ser interpretado pelo destinatário do que propriamente pela transmissão de sua própria subjetividade. O locutor japonês é aquele que procura buscar, no outro, o seu padrão de julgamento e de estabelecimento de sua atitude de fala.

Paralelamente, esse controle de si mesmo, em prol do destinatário, e a imprecisão da intencionalidade do locutor provocam a necessidade complusória da efetivação do sasshi ("percepção" ou "intuição"; a compreensão e captação daquilo que não foi expresso) por parte do destinatário, para que a interação se torne possível. A falta de explicitação de sua intencionalidade por parte do locutor é suprida pelo destinatário, pelo uso da máxima do sasshi, um outro recurso de persuasão.

Diante disso, estabelece-se a importância da figura do destinatário na estrutura de interação dos japoneses. E esse destinatário tem duplo papel: por um lado, o de ser o objeto primordial de preocupações para o locutor enunciar e, de outro, o de permitir a efetivação de um ato de fala mediante complementação das interpretações das intencionalidades do locutor através do sasshi.

Segundo tal ponto de vista, um ato de fala em língua japonesa parece sugerir que a perlocução aparece mais claramente do que a ilocução, dado que a sua natureza argumentativa se baseia na preocupação constante com o destinatário. Mas, como em qualquer língua, não se pode estudar o problema das modalidades japonesas analisando apenas $\mathrm{o}$ ato ilocucionário, sem que se leve em conta também o perlocucionário. $\mathrm{O}$ conceito de sasshi se torna, então, uma habilidade do destinatário, fundamental para a efetivação da interação. É um valor ético que deve ser parte integrante do destinatário e no qual o destinador confia previamente. É um acordo tácito, cuja inexistência poderá até, em certos casos, tornar inviável a comunicação em japonês.

Contrapondo-se a essa exigência feita ao destinatário, há que se considerar, também, certos deveres e obrigações inerentes ao locutor: a sua consideração (omoiyari), a sua preocupação (kikubarilkokorozukai), a cerimônia (enryo) para com o interlocutor.

Tal sistema de regras impõe a todos os usuários da língua japonesa o conhecimento prévio e amplo do sistema convencional de argumentação e de persuasão. Mesmo os 
problemas mais complexos serão solucionados de forma casual, estética e, sobretudo, de maneira implicitada.

Usando outras palavras, Kindaichi (1980) dizia que "a língua japonesa é uma língua que tem suas bases fundadas no princípio de fazer o destinatário intuir e de confiar na sua percepção" (p. 126). Da mesma forma, Haga (1979) enfatizava a intuição do destinatário como fator primordial, constituindo a máxima contida em kan'de aiteno kokoroo yomu ("apreender os sentimentos dos outros através da intuição"), um valor estético altamente apreciado na realização da interação linguiística e social entre os japoneses.

Com efeito, notar-se-á que, na língua japonesa, o discurso que se organiza em torno do destinatário se realiza em concomitância com o discurso centrado no locutor, sendo o conjunto dos dois tipos a unidade mínima significativa de interação. A apreensão das intenções do locutor se realiza mais pela habilidade de sasshi do alocutário do que propriamente pelas formas modais explicitadas pelo primeiro.

Já se chamou a atenção para o fato de que o locutor procura, no momento da enunciação, o máximo de controle de suas paixões. Mas vale a pena mencionar, ainda, que Sakakura aponta, como causa dessa característica, a influência da moral confucionista que perdurou, durante um longo período, na época feudal do Japão (era Edo - século XVI-XVII), fixando-se como uma postura a ser seguida pelo Bushidô ("a ética dos samurais"). Acrescente-se a isso que o próprio sistema das relações humanas e a dinâmica da coletividade japonesas não se baseavam na vontade individual, nem na exteriorização das idéias entre os indivíduos. Os japoneses, diz Haga, não acreditam que o homem possa ou deva intervir nos acontecimentos e controlar a coletividade ou um outro indivíduo. "A tese de Barnlund (1973), segundo a qual comunicar significa, a rigor, mudar o destinatário, tende a soar estranho aos ouvidos da maioria dos japoneses" afirma Haga (1979, p. 29). A interpretação mais correta, entretanto, parece estar na idéia de que o japonês realiza sim o ato perlocucionário, mas procurando mostrar não querer agir ou alterar o comportamento do outro.

Como conseqüência, surgiram as atitudes de respeito ao outro, às quais já se referiu anteriormente: preocupação com o destinatário, cerimônia, benevolência, kaode waratte kokorode naku ("mostrar um sorriso no rosto e chorar no coração") etc. No lugar da explicitação da intenção, desenvolveram-se enunciados com formas predicativas vagas cujo intuito está, exatamente, em evitar as afirmações enérgicas e as declarações enfáticas. Basta verificar as formas predicativas mais comuns, utilizadas no enunciados japoneses: dewa naideshôka ("será que não se deve dizer que.."), dewa naikato omoimasuga ("penso que talvez seja..."), to iesôna kiga shimasu ("tenho a impressão de que talvez se possa dizer que..."), to uketorarekanenai nodewa naikato omoerundesuga ("tem-se a possibilidade de se pensar que talvez não se possa deixar de entender que...") etc. Verifica-se que as formas apresentadas constituem atenuadores modais que registram essa ideologia do "não afirmar categoricamente" e do atenuar a subjetividade do locutor, em nome do respeito ao destinatário.

Convém mencionar, ainda, dois traços que constituem fatores importantes para a investigação do modo de expressar do japonês: os conceitos de igualdade/desigualdade e, como consequiência destes, o de hierarquia, dentro da cultura japonesa. 
O sistema feudal e a filosofia confuciana criaram, no Japão, uma hierarquia rígida e estável, baseada no status e no fator idade dos indivíduos. E esse sistema hierárquico deixou sua forte marca nos japoneses. "Assumir a posição devida" tornou-se um fator fundamental, cujo valor regula todo o mecanismo social. Parece procedente, quando Ruth Benedict (1988) diz que, enquanto os ocidentais cultuam a fé na liberdade e na igualdade, os japoneses demonstram sua confiança na ordem e na hierarquia. Para os japoneses, afirma a antropóloga,

a desigualdade tem sido, durante séculos, a regra de sua vida organizada [...] e a hierarquia é tão natural para eles como o respirar. Não se trata, contudo, de um simples autoritarismo ocidental. [...] O Japão, com toda a sua recente ocidentalização, é ainda uma sociedade aristocrática. Cada cumprimento, cada contato deve indicar a espécie de grau de distância social entre os homens. Cada vez que um homem diz para outro "Coma" ou "Sente-se", usa palavras diferentes, conforme esteja se dirigindo familiarmente a alguém ou falando com um inferior ou superior. Existe um "você" diferente que deve ser usado em cada caso e os verbos têm radicais diferentes. Os japoneses têm, em outras palavras, o que se chama de uma "linguagem de respeito", tal qual muitos outros povos do Pacífico, acompanhada de mesuras e genuflexões apropriadas. Todo esse procedimento é governado por regras e convenções meticulosas; não é apenas necessário saber a quem é feita a mesura, como também a sua freqüência. Uma mesura correta e apropriada para um anfitrião seria considerada como um insulto por outro em relação ligeiramente diversa com o convidado. (O Crisântemo e a Espada, pp. 46-47).

A conduta apropriada deve ter como base não só as diferenças de classe, mas também a observância de outros fatores, tais como a idade, o sexo, os laços de família, ou relações de intimidade ou distanciamento formal etc.

É, contudo, interessante notar que uma pesquisa de opinião pública revelou que mais de $90 \%$ dos japoneses se considera membro pertencente à classe média japonesa. Christopher (1984) aponta duas razões que justificam o resultado da pesquisa: primeiro, porque o Japão é uma sociedade que apresenta pequena desigualdade na divisão de renda entre seus membros (o empresário percebe rendimentos que são, no máximo, seis vezes maior que o salário do trabalhador braçal); em segundo, porque os mais ricos convivem com os mais pobres de forma harmônica, misturando suas residências mais suntuosas com as mais modestas, situadas num único lugar, compartilhando um senso comunitário de ocupação regional.

Mas, apesar dessa "igualdade econômica" a hierarquia, como sinônimo de respeito ao mais velho ou ao superior "por costume" ou "por educação" é um símbolo a ser preservado para uma conduta de vida conveniente. A posição social do japonês é estabelecida, segundo Christopher (1984), em face do lugar que cada indivíduo acredita ocupar dentro da hierarquia específica do Japão. E o que ilustra essa postura, de forma mais adequada, é, de acordo com o autor, o costume da troca de cartões de apresentação entre a grande maioria dos japoneses. E a razão é simples. Para os japoneses, o desconhecimento da posição ou papel social que o parceiro ocupa dentro da coletividade ou o desconhecimento do tipo de comunidade a que o outro pertence, prejudica a escolha correta da atitude ou o grau de respeito que se lhe deve atribuir. 
E, em meio a essas circunstâncias, a linguagem de tratamento é o instrumento lingüístico dos mais eficazes para preservar, de forma adequada, as relações entre os indivíduos. Sakakura (1972) denomina-a "linguagem de respeito e distanciamento interpessoal" (Keiengo).

As características levantadas (e outras) poderão servir de subsídios importantes no esclarecimento e na explicação do funcionamento do mecanismo argumentativo da língua japonesa, devendo, portanto estar sempre correlacionadas aos seus métodos de investigação.

\section{Bibliografia}

AIDA, Yûji. Nihonjinno Ishiki Kôzô.Tóquio, Kôdansha, 1970.

ARAKI, Hiroyuki. Nihonjinno Kôdô Yôshiki. Tóquio, Kôdansha Gengo Shinsho, 1973. Nihongokara Nihonjin'o Kangaeru.Tóquio, Asahi Shinbunsha, 1980. Nihonjinno Shinjô Ronri. Tóquio, Kôdansha, 1976.

BaRnLund, Dean C. Nihonjinno Hyôgen Kôzô (Public and Private Self in Japan and the United States). Trad. japonesa de Sen Nishiyama. Tóquio, Saimaru Shuppankai, 1973.

BENEDICT, Ruth. O Crisântemo e a Espacla. São Paulo, Perspectiva, 1988.

BENVENISTE, Émile. Problèmes de linguistique générale II. Paris, Gallimard, 1974.

CHRISTOPHER, Robert. The Japanese Mind. (Trad. japonesa de Jirô Tokuyama). Tóquio, Kôdansha, 1984.

DuCrot, Oswald. Princípios de Semântica Lingüistica. (Dizer e não Dizer). São Paulo, Cultrix, 1977.

O Dizer e o Dito. São Paulo, Pontes Editora, 1983.

"Topoï et Formes topiques". In: Bulletin d'Études de Linguistique Française, $\mathrm{n}$.

22. Tóquio, 1988. pp. 1-14.

HAGA, Yasushi. Nihonjinno Hyôgen Shinri. Tóquio, Chûôkôronsha, 1979.

KINDAICHI, Haruhiko. Nihongono Tokushitsu. Tóquio, NHK Daigaku Kôza, 1980.

KunıHIRo, Tetsuya. Nichieigo Hikaku Kôza - Bunkato Shakai. vol. 5. Tóquio, Taishûkan Shoten, 1984.

MinamI, Fujio. "Nihongowa Donna Kotobaka". In: Nihongono Tokushoku, col. Kotoba Shiriizu, n. 10. Tóquio, Bunkachô, 1983. pp. 34-45.

MIYAJI, Yutaka. Gendai Hyôgen Kô. Tóquio, Kyôbunsha, 1971.

OKUYAMA, Masurô (org.). Hanashiaito Taiwa - Nihongono Kekkanni tsuite. Tóquio, Tôkyôdô Shuppan, 1972.

ÔNo, Susumu. "Nihonjinno Shikôto Nihongo". In: Gengo, vol. 25. Tóquio, Iwanami Shoten, dez. 1967, pp. 1-13.

SAKaKURA, Atsuyoshi. "Nihonjinno Kanjôto Gengo". In:Gengo, vol. 1, n. 2. Tóquio, Taishûkan Shoten, mai. 1972, pp. 12-19. 